\title{
Research on Application of Hybrid Energy Storage Device in Solar Photovoltaic Power Generation System
}

\author{
Huaizhong Chen \\ Zhejiang Industry Polytechnic College, Shaoxing, China \\ Chz702@163.com
}

Keywords: Bidirectional converter; Energy storage; Photovoltaic power; Super-capacitor

\begin{abstract}
Super-capacitor has advantages of small and restricted charging conditions, long cycle life and high battery specific energy. The advantages are utilized; The maximum power point of solar battery is combined for tracing control circuits. Application of hybrid energy storage of super-capacitor and battery in independent photovoltaic system is experimentally studied. The results show that solar batteries still can be charged stably under the condition of larger external environment fluctuation, thereby improving the utilization rate of the system, reducing battery cycles, and prolonging the service life of the battery. The structure is characterized by less parts, low cost, no transformer loss, high efficiency, easy package and integration
\end{abstract}

\section{Introduction}

Photovoltaic battery output is greatly affected by light and temperature. Its output power has low stability and predictability. Currently, lead-acid battery is the energy storage device commonly adopted for photovoltaic power generation systems in independent systems. However, it has short cycle life, low specific power, high maintenance quantity and other invincible defects. Output energy of solar photovoltaic power generation is extremely low and stable, therefore the battery becomes invalid too early or the capacity is lost, thereby further increasing the cost of photovoltaic system. Battery cost accounts for $20 \%$ to $25 \%$ of PV system cost. Super-capacitor is a novel energy storage device. It has advantages of greater specific power of conventional capacitor and higher specific power of rechargeable battery on one hand, the super-capacitor also can be charged and discharged rapidly with long service life.

However, super-capacitor has lower specific energy currently. It is difficult to realize large capacity energy storage. If super-capacitor and battery are used together, high specific energy of battery is combined with features of super-capacitor, namely high specific power and long cycle life. The efficiency of the energy storage system can be increased, the utilization rate of the battery can be increased, battery charge and discharge times can be reduced, and the service life can be increased [1-2].

\section{System Analysis}

Super capacitor is a new type of energy device which appears in recent years, which is different from the conventional capacitor, whose capacity is up to Fala and even thousands of Fala. The utility model has the advantages of high power density of conventional capacitors, high specific energy of charging batteries, fast charging and discharging and long service life, and the utility model is a novel, efficient and practical energy storage device.

Super-capacitor has excellent charge and discharge performance. It can be rapidly charged to ideal voltage value at fast speed within rated voltage scope. All electricity can be discharged during discharging. The battery cannot be damaged due to fast charging and discharging. Photovoltaic power generation system is affected by climate and other natural factors. Its power generation output power has low stability and predictability, which is mainly manifested by output current fluctuation. Charging current is too large, and the battery may suffer from polarization phenomenon, thereby active materials on the polar plate may be lost. Temperature rise phenomena can be aggravated. In addition, battery charging current is always in a fluctuation state due to 
discontinuous generation power, thereby accelerating aging process, and shortening cycle service life. Super-capacitor with certain capacity is configured. Energy flowing process from super-capacitor to battery is controlled by a controller. Advantage of high specific power in super-capacitor can be fully exerted. Charging and discharging current of the battery can be optimized. The energy storage ability of super-capacitor also can be utilized for reducing charging and discharging cycles [3-4].

\section{System Structure Design}

The super capacitor and the battery are usually used in parallel with the Fed energy, and generally have a parallel connection mode. In active energy storage structure, system configuration and design process control have greater flexibility, to storage to system performance improvement is also effective, but the circuit structure is complex, high cost, high energy consumption, of generally small independent photovoltaic power system does not apply. The end voltage of the super capacitor will rise or fall in the charging and discharging process, so it is generally not directly connected with the photovoltaic array and the load.

Battery and super-capacitor are adopted for forming hydroid energy storage independent photovoltaic system. It is mainly composed of photovoltaic array, maximum power tracking MPPT control, charging controller, battery, super-capacitor, bidirectional DC/DC converter, load and other parts as shown in Fig. 1.

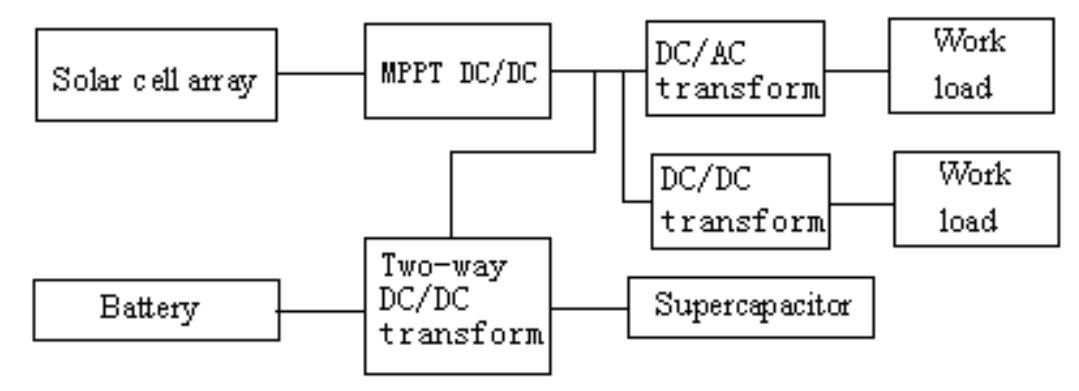

Figure 1. Hybrid energy storage stand-alone PV system structure diagram

Wherein, the charging controller is used for controlling the energy of the photovoltaic array. Electric energy is output in certain mode according to actual state of the system, namely current limit mode and constant voltage mode. The system is also equipped with a super-capacitor in certain capacity. It has certain energy storage capacity, which can reduce charge and discharge small cycle times of batteries and output electric energy of the photovoltaic can be filtered. Discharge current of battery can be optimized. The battery can be connected with DC load or AC load through an inverter as main energy storage device of the system. The battery and super-capacitor can provide required energy and power for DC load. Bidirectional DC/DC converter is the control link for conveying energy from super-capacitor to battery. It is controlled for optimizing operating environment of the battery as far as possible and prolonging service life thereof. The battery is connected with the super-capacitor through bidirectional DC/DC converter. Non-isolated half-bridge structure is adopted for bidirectional DC/DC converter. The structure is characterized by less parts, low cost, no transformer loss, high efficiency, easy package and integration [5-6].

\section{MPPT Control}

The maximum power point tracking is that the controller can generate voltage real-time detection of solar panels, and track the appropriate voltage and current value, the system with the highest output efficiency. Fig. 2 is volt battery characteristic curve [7]. 


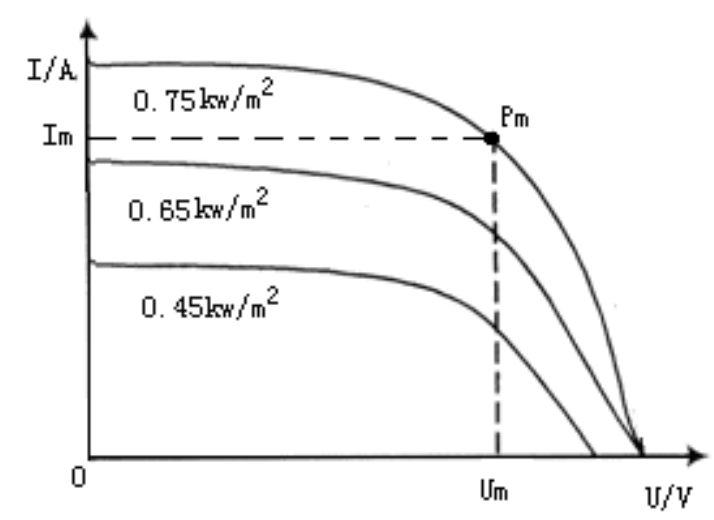

Figure 2. Characteristic curve when $\mathrm{T}=250$

From above picture, we can see that, in a certain temperature and light intensities, different solar light intensity curve can find a Pm maximum power output point, assuming a solar photovoltaic battery work almost always work hours at the maximum power point $\mathrm{Pm}$, it can greatly improve the efficiency of the solar photovoltaic energy conversion efficiency rise, how to use the best way to find the maximum power point, and work in the vicinity of the maximum power, maximum power point automatic optimization [8]..

\section{Control Strategy}

The system can be divided into eight modes through detecting battery terminal voltage and terminal current, photovoltaic battery output voltage, super-capacitor terminal voltage, DC bus voltage, photovoltaic battery output power, output current and output rated power.

Working mode 1: When the system is started to work normally, the unidirectional converter is operated under maximum power tracking MPPT mode, thereby guaranteeing that the photovoltaic battery can output the maximum power. If the photovoltaic battery is less than the load power requirements, the battery provides insufficient power, and stable voltage of DC bus is guaranteed through controlling voltage and inductance current on the high voltage side of the bidirectional converter 1.

Working mode 2: Unidirectional converter is operated under MPPT mode, if the photovoltaic battery is greater than the load power requirements, excessive energy can be used for charging the battery and super-capacitor. Bidirectional converter 1 is operated under the Boost mode, thereby ensuring stability of DC bus voltage.

Working mode 3: If load mutation is detected under the condition of working mode 1 , the bidirectional converter 2 is started and operated under Boost mode provide load with impact power, thereby ensuring the stability of DC bus voltage.

Working mode 4: When load mutation is discovered under the condition of working mode 2. Charging current of the system is reduced, and energy flows at the opposite direction.

Working mode 5: If the battery charging reaches overcharge voltage or charging current reaches the maximum allowable charging current, the unidirectional converter working is operated under constant voltage mode, the output voltage is controlled to guarantee the stability of DC bus voltage, the bidirectional converter 1 is operated in Buck mode for charging the battery.

Working mode 6: The photovoltaic battery has no output, the unidirectional converter stops working, the bidirectional converter 1 is operated in Boost mode, the battery can separately supply power for the load, and the output voltage can be controlled, thereby ensuring stable bus bar voltage [9-10].

\section{Conclusion}

In the paper, structure performance and control strategy of solar photovoltaic power generation hybrid power supply system with super-capacitor and battery as hybrid energy storage system are 
studied. Simulation results show that when generation power of photovoltaic power generation system is fluctuated, the hybrid energy storage system is always in the optimized charging and discharging state through control by the bidirectional converter, thereby ensuring stable operation of the load. In addition, the charging current of the battery can be effectively controlled through the bidirectional converter, thereby keeping the charging current in the maximum acceptable charging current, prolonging the service life of the battery, and realizing quick charging of the battery.

\section{Acknowledgements}

This work is supported by scientific research funded project of Science Technology Department of Zhejiang Province (2015C31128).

\section{References}

[1] Y Hang, Master degree thesis of Chongqing University, Vol.43(2011), No. 3, p. 567-575.

[2] Cegnar E J, Hess H L and Johnson B K, Nineteenth Annual IEEE Applied Power Electronics Conference and Exposition, Vol.23(2004), No. 1, p. 1160-1164.

[3] Dixon J W, Oriuzar M E, IEEE Aerospace and Electronic Systems Magazine, Vol.17(2002), No. 8, p. 16-21.

[4] Mellor P H, Schofield N, IEE Seminar 11 on Electric, Hybrid and Fuel Cell Vehicles. Sheffield Univ England, Vol.17 (2012), No. 8, p. 1-5.

[5] Ahmed E M, Shoyama M, The 2011 IEEE Ninth International Conference on Power Electronics and Drive Systems. Vol.1 (2011), No. 2, p. 891-894.

[6] Sun K, Zhang L, IEEE Transactions on Power Electronics, Vol.26(2011), No.10, p. 3032-3045.

[7] Vulturescu, S. Butterbach, Electrical Machines Conference, Vol.21 (2010), No. 1, p. 147-152.

[8] Sun K, Zhang L, Xing Y, IEEE Transactions on Power Electronics, Vol.26(2011), No. 10, p.3032-3045.

[9] Si Jiang, The 2011 Twenty-Sixth Annual IEEE on Applied Power Electronics Conference and Exposition, 2011:401-406.

[10] Vulturescu, S.Butterbach, Electrical Machines Conference, Vol.21 (2012), No.1, p.147-152. 